\title{
Durability of Esophageal Motor Disorders Identified on High-Resolution Esophageal Manometry: A Case Series
}

\author{
Annumeet Sandhu - Mohamed Eisa - Takahisa Yamasaki • \\ Fahmi Shibli · Ronnie Fass
}

Received: February 14, 2020 / Published online: April 13, 2020

(C) The Author(s) 2020

\begin{abstract}
Background/Aim: Diagnosis of esophageal motor disorders using high-resolution esophageal manometry (HREM) may result in medical, endoscopic or surgical intervention. However, prior to any intervention, durability of the HREM findings should be established. The aim of this case series was to assess 25 patients who had undergone HREM twice, at least 6 months apart, and to determine the durability of the initial manometric diagnosis.

Methods and Patients: This is a case series of 25 patients who underwent HREM at least twice, 6 months apart, at a large safety net hospital. All patients were evaluated in between the tests for any clinical intervention. Demographics, patients' indication for HREM and clinical presentation were documented as well.
\end{abstract}

Digital Features To view digital features for this article go to https://doi.org/10.6084/m9.figshare.12034650.

\footnotetext{
A. Sandhu - M. Eisa - T. Yamasaki · F. Shibli .

R. Fass $(\square)$

Division of Gastroenterology and Hepatology, The

Esophageal and Swallowing Center, MetroHealth

Medical Center, Case Western Reserve University,

Cleveland, $\mathrm{OH}, \mathrm{USA}$

e-mail: ronnie.fass@gmail.com
}

Results: Of the 25 patients, HREM results improved in $32 \%$, worsened in $20 \%$ and were unchanged in $48 \%$. Some interventions were employed between the first and second HREM diagnosis. Those associated with an improved diagnosis included doubling the proton pump inhibitor (PPI) dose, re-starting a PPI, adding a histamine 2 blocker ( $\mathrm{H} 2$ blocker) and use of empiric dilation.

Conclusions: In this case series, about half of the patients undergoing two esophageal manometries, at least 6 months apart, demonstrated lack of durability of their initially diagnosed esophageal motor disorder.

Keywords: Dysphagia; Esophageal manometry; Esophageal motility; Heartburn; Proton pump inhibitors 


\section{Key Summary Points}

Durability of non-achalasic esophageal motor disorders remains unknown.

Presently, the assumption is that the presence of hypercontractile or hypocontractile esophageal motor disorder on first esophageal manometry is a long-term diagnosis.

In this study we evaluated patients with esophageal motor disorders who underwent a repeat manometry at least 6 months apart.

The study demonstrated that $50 \%$ of the patients assessed had either a normal or a different esophageal motor disorder on a repeat esophageal manometry.

\section{INTRODUCTION}

Today, HREM is considered the gold standard for diagnosing esophageal motility disorders [1]. The Chicago classification was developed to help interpret the high-resolution manometric findings and thus facilitate diagnosis of esophageal motor disorders. Esophageal motility disorders have been classified into major (distal esophageal spasm, jackhammer esophagus, achalasia, esophagogastric junction outflow obstruction and absent contractility) and minor (ineffective esophageal motility and fragmented peristalsis) [2]. Despite the advancement in the diagnosis of esophageal motility disorders using HREM, the technique has its own limitations. HREM still does not provide a full explanation of non-obstructive dysphagia and does not incorporate the effect of age, obesity, body position and esophageal length on esophageal function measurements [3]. Also, the Chicago classification does not include abnormalities of the upper esophageal sphincter (UES) and surgically induced motor disorders [4]. Wang et al. [4] calculated that $32 \%$ of the patients who underwent HREM had a diagnosis or abnormalities not mentioned in the Chicago classification.

A subset of patients will undergo repeated HREMs because of failure of therapy, new or worsening symptoms or concerns about progression of the disease. However, there are very limited data in the literature on the durability of non-achalasic esophageal motility disorders and whether in some cases the motility disorder is transient or may regress or progress to a more severe disease. This has an important clinical impact on our management of non-achalasic esophageal motor disorders. If all or some of the non-achalasic esophageal motor disorders are not durable, then maybe therapeutic interventions should be held back and repeat HREM at a certain time interval should become the standard of care.

It has been demonstrated that esophageal motility disorders may evolve over time. Dalton et al. demonstrated that nutcracker esophagus diagnosis may change over time. The authors found that of the 17 patients who were initially diagnosed as having nutcracker esophagus, only $54 \%$ remained with the same diagnosis on subsequent manometry after a 32-month period [5]. There are several reports of patients with an initial diagnosis of nutcracker esophagus who have undergone transition to diffuse esophageal spasm or achalasia [6-8]. Moreover, Abdallah et al. [9] reported a case of a patient with jackhammer esophagus in the first HREM that evolved within 1 year into type II achalasia.

In this case series, we aimed to determine the durability of initially diagnosed esophageal motor disorders by evaluating patients who underwent HREM twice at least 6 months apart because symptoms persisted or worsened. We further determined if the esophageal motor disorders regressed, progressed or remained the same over time. In addition, we evaluated the factors associated with regression, progression or no change in diagnosis overtime.

\section{METHODS}

Consecutive patients who underwent HREM twice, at least 6 months apart, between 2014 and 2017 were included in this study. Patients 
Table 1 Demographic characteristics of both groups

\begin{tabular}{|c|c|c|c|c|}
\hline & \multicolumn{2}{|c|}{$\begin{array}{l}\text { Change in HREM diagnosis } \\
n=13(52 \%)\end{array}$} & \multicolumn{2}{|c|}{$\begin{array}{l}\text { No change in HREM diagnosis } \\
n=12(48 \%)\end{array}$} \\
\hline \multicolumn{5}{|l|}{ Gender, $n(\%)$} \\
\hline Female & \multicolumn{2}{|c|}{$11(85)$} & \multicolumn{2}{|l|}{$7(58)$} \\
\hline Male & \multicolumn{2}{|c|}{$2(15)$} & \multicolumn{2}{|l|}{$5(42)$} \\
\hline Age, (years) mean $( \pm S D)$ & \multicolumn{2}{|c|}{$56.31(12.41 \pm \mathrm{SD})$} & \multicolumn{2}{|c|}{$59(10.07 \pm \mathrm{SD})$} \\
\hline \multicolumn{5}{|l|}{ Ethnicity, $n(\%)$} \\
\hline Caucasian & \multicolumn{2}{|c|}{$5(38)$} & \multicolumn{2}{|l|}{$8(67)$} \\
\hline Afro-American & \multicolumn{2}{|c|}{$8(62)$} & \multicolumn{2}{|l|}{$4(33)$} \\
\hline $\mathrm{BMI}$, mean $( \pm \mathrm{SD}), \mathrm{kg} / \mathrm{m}^{2}$ & \multicolumn{2}{|c|}{$33.15(7.26 \pm \mathrm{SD})$} & \multicolumn{2}{|c|}{$34.28(5.36 \pm \mathrm{SD})$} \\
\hline \multicolumn{5}{|l|}{ Comorbidities, $n(\%)$} \\
\hline $\mathrm{DM}$ & \multicolumn{2}{|c|}{$4(31)$} & \multicolumn{2}{|l|}{$4(33)$} \\
\hline HTN & \multicolumn{2}{|c|}{$5(38)$} & \multicolumn{2}{|l|}{$5(42)$} \\
\hline GERD & \multicolumn{2}{|c|}{$6(46)$} & \multicolumn{2}{|l|}{$4(33)$} \\
\hline Narcotics use & \multicolumn{2}{|c|}{$1(7.7)$} & \multicolumn{2}{|l|}{$2(17)$} \\
\hline Benzodiazepines use & \multicolumn{2}{|c|}{$1(7.7)$} & \multicolumn{2}{|l|}{ None } \\
\hline \multirow[t]{2}{*}{ Other* } & \multicolumn{2}{|c|}{$12(92)$} & \multicolumn{2}{|l|}{$10(83)$} \\
\hline & 1 st & 2nd & 1 st & 2nd \\
\hline \multicolumn{5}{|l|}{ Indication, $n(\%)$} \\
\hline Dysphagia & $12(92)$ & $11(85)$ & $10(83)$ & $11(91.6)$ \\
\hline Heartburn & $2(15)$ & None & $1(8.3)$ & None \\
\hline Chest pain & None & $2(15)$ & None & None \\
\hline Globus & $2(15)$ & $2(15)$ & $4(33)$ & $4(33)$ \\
\hline Other** & $1(7.7)$ & $2(15)$ & $2(16.6)$ & $1(8.3)$ \\
\hline
\end{tabular}

HTN hypertension, DM diabetes mellitus, GERD gastroesophageal reflux disease

*Obstructive sleep apnea; transient ischemic attack; acquired immunodeficiency disease/human immunodeficiency virus; small intestine bacterial overgrowth; nonalcoholic fatty liver disease; primary biliary cirrhosis; autoimmune hepatitis; peptic ulcer disease; systemic lupus erythromatosus; coronary artery disease; depression; anxiety; Sjogren's; chronic lung disease; hypothyroid

${ }^{* *}$ Weight loss; bloating; presurgical evaluation

were selected based on chart review using the EPIC electronic medical record system at a large safety net medical center. Patients who demonstrated normal motility or achalasia in the first HREM were excluded. In addition, patients who underwent an upper foregut surgery or surgical endoscopy and who demonstrated severe comorbidity were excluded as well. The HREM diagnosis was based on the Chicago classification v3.0. Demographic data, 


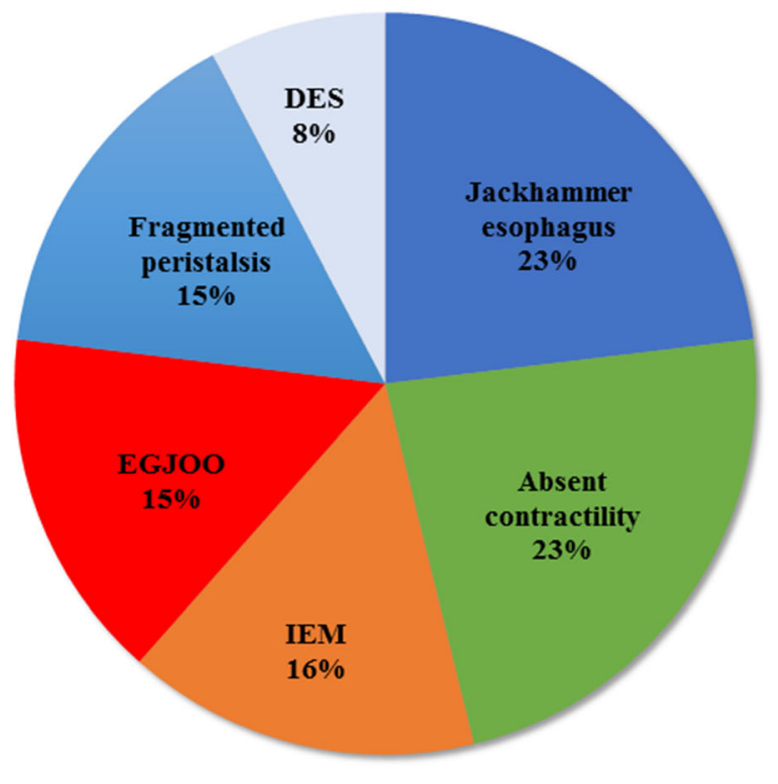

$1^{\text {st }}$ diagnosis

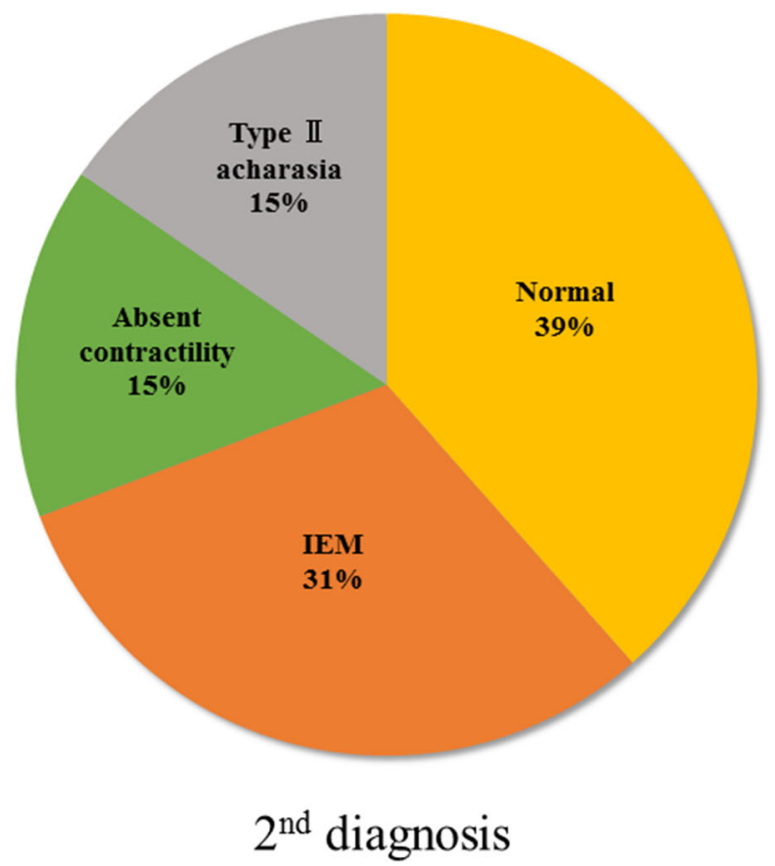

Fig. 1 Changes in high-resolution esophageal manometry (HREM) diagnoses in patients undergoing a second test up to 36 months later

medications and manometric results were documented and analyzed. This study was approved by the institutional review board of MetroHealth Medical Center. The initial and subsequent HREM diagnosis was made by a highly trained expert in the area of esophageal motor disorders.

\section{Statistical Analysis}

Numeric variables are expressed as mean $\pm \mathrm{s}$ tandard deviation, counts $(n)$, ranges (minimum-maximum), median and quartile (q1; q3). Categorial variables are described using frequencies $(n)$ and percentages (\%). The calculations were performed using Microsoft Excel 2016.

\section{RESULTS}

Twenty-five patients underwent two HREM studies at least 6 months apart during the study period. Table 1 shows the demographics of the patient cohort. Of those, 13 (52\%) patients had a different diagnosis on their second HREM than on their first one. Five (38\%) demonstrated progression and eight (62\%) regression of the esophageal motor abnormality (Fig. 1). Repeat HREM in all patients was driven by continuous or worsening of symptoms despite various therapeutic interventions. Table 2 shows the patients who demonstrated a change in HREM diagnosis from the first to the second test. Patients listed in Table 3 are those who did not have any change in HREM diagnosis between the two tests.

The changes in management that have been associated with improved diagnoses (regression) included doubling the proton pump inhibitor dose, re-starting a proton pump inhibitor, adding an $\mathrm{H} 2$ blocker and empiric dilation. Other interventions that were documented between the two HREM studies in those who demonstrated improvement included: lifestyle modifications, addition of a tricyclic anti-depressant and use of prokinetic agents (metoclopramide/ erythromycin). However, these were only employed in two out of eight patients who demonstrated improvement in diagnosis between the two HREM studies. 


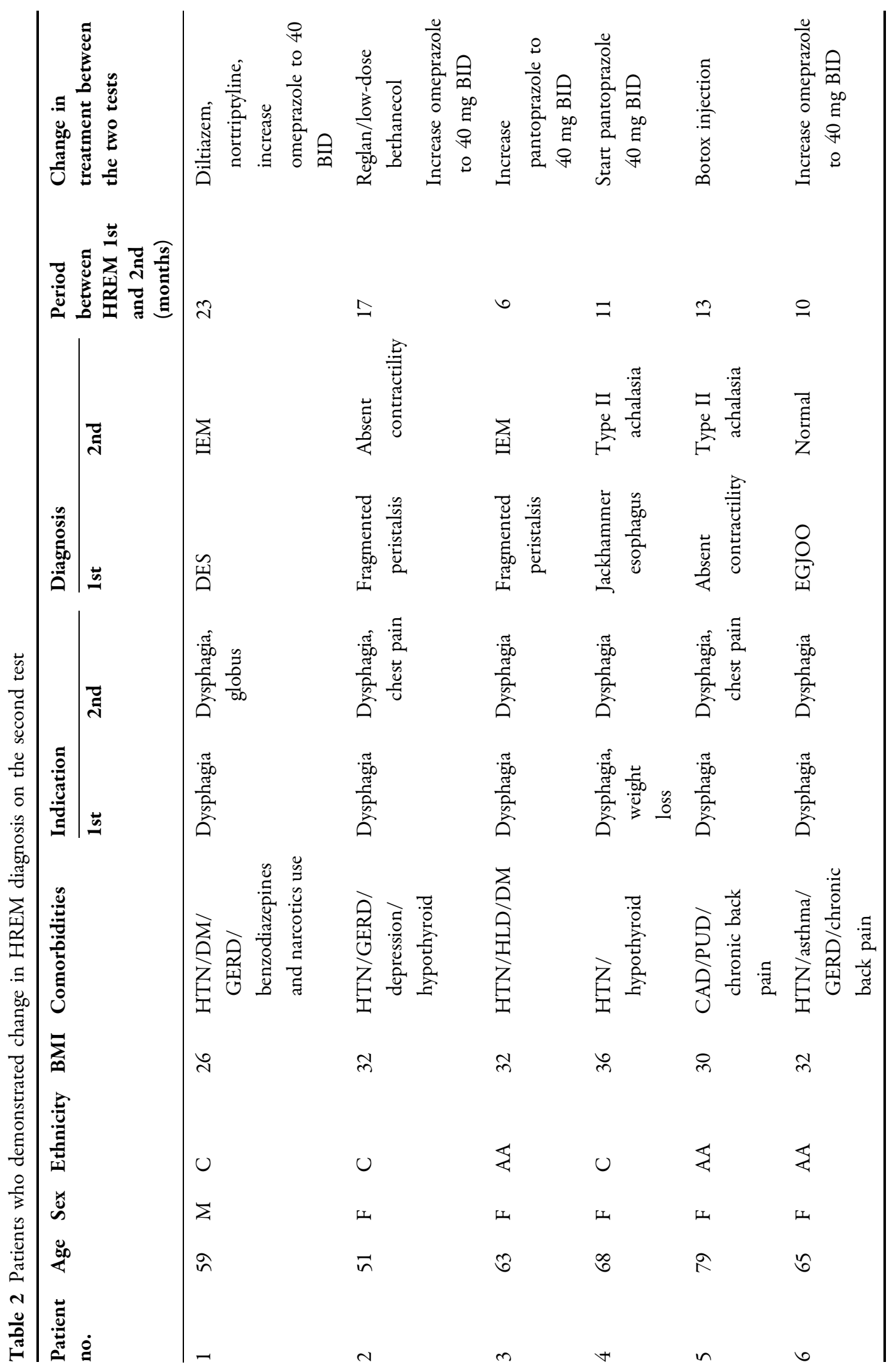




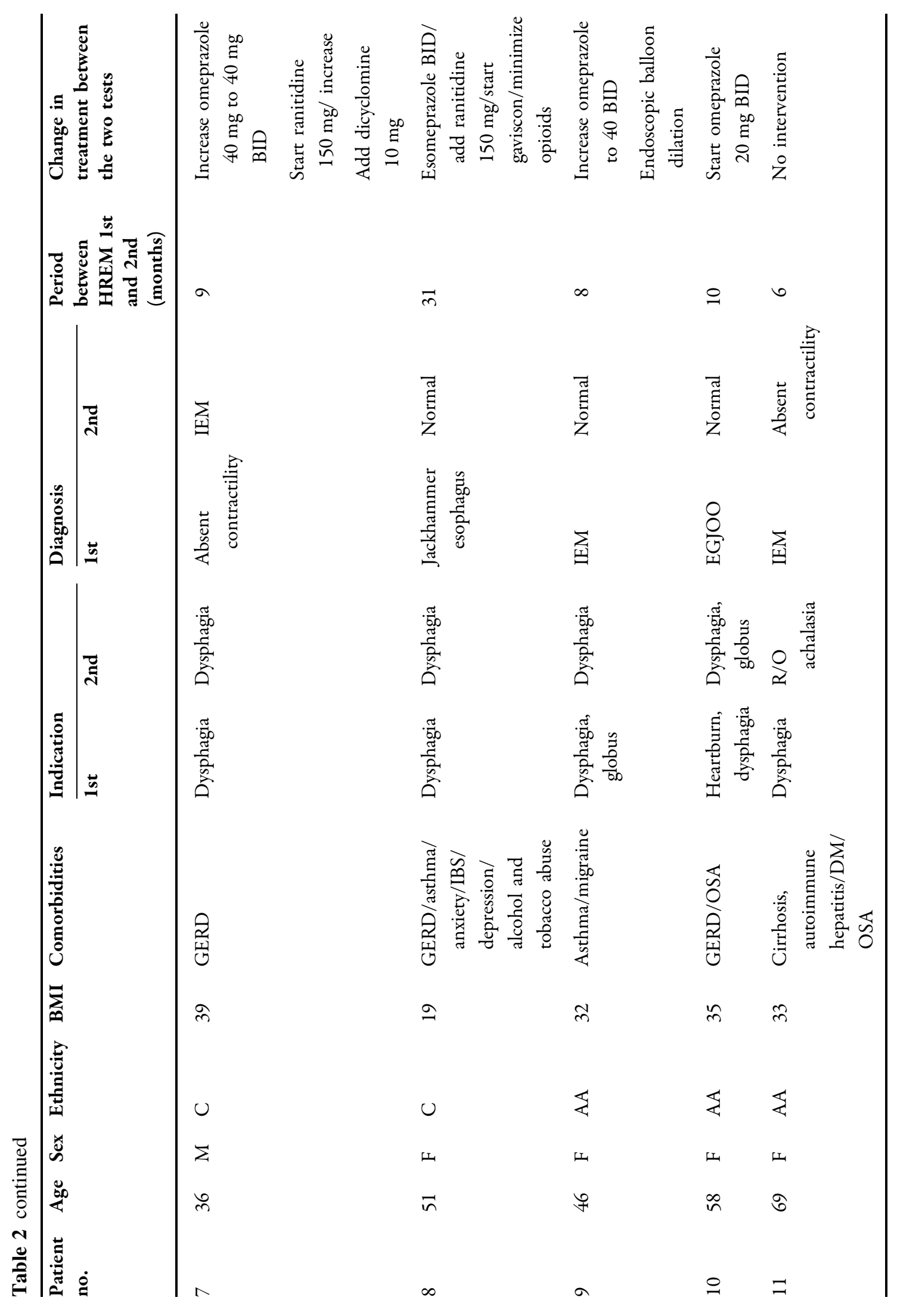




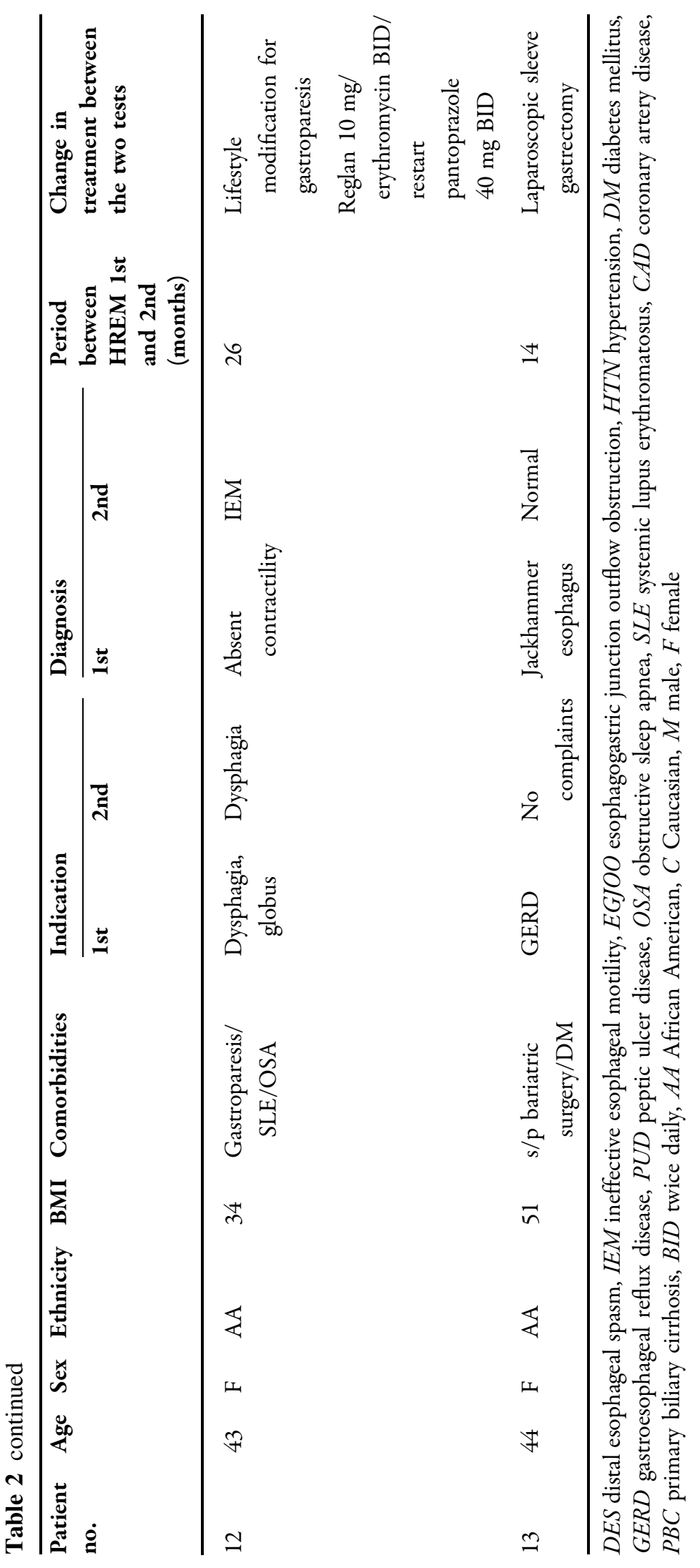




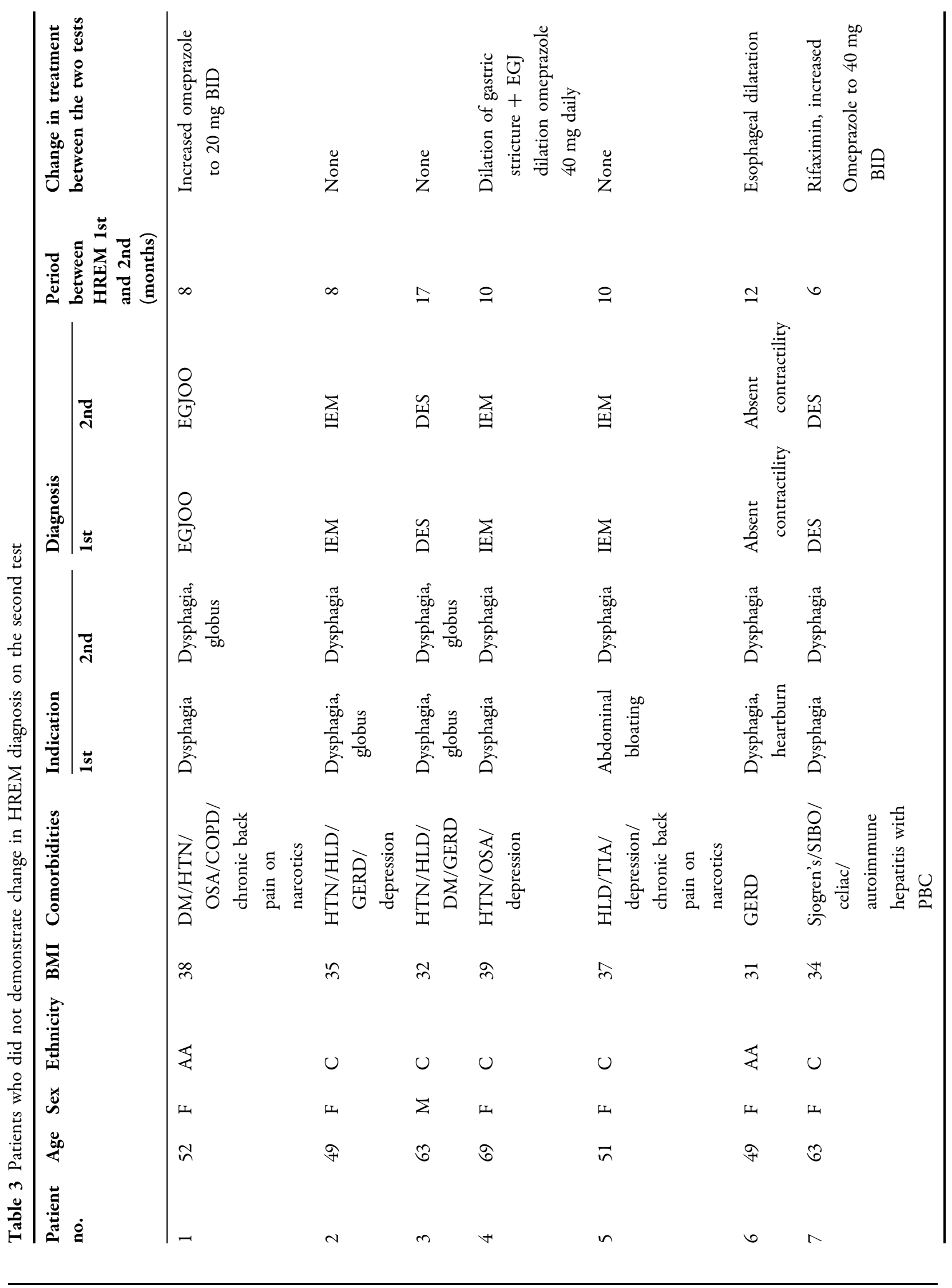




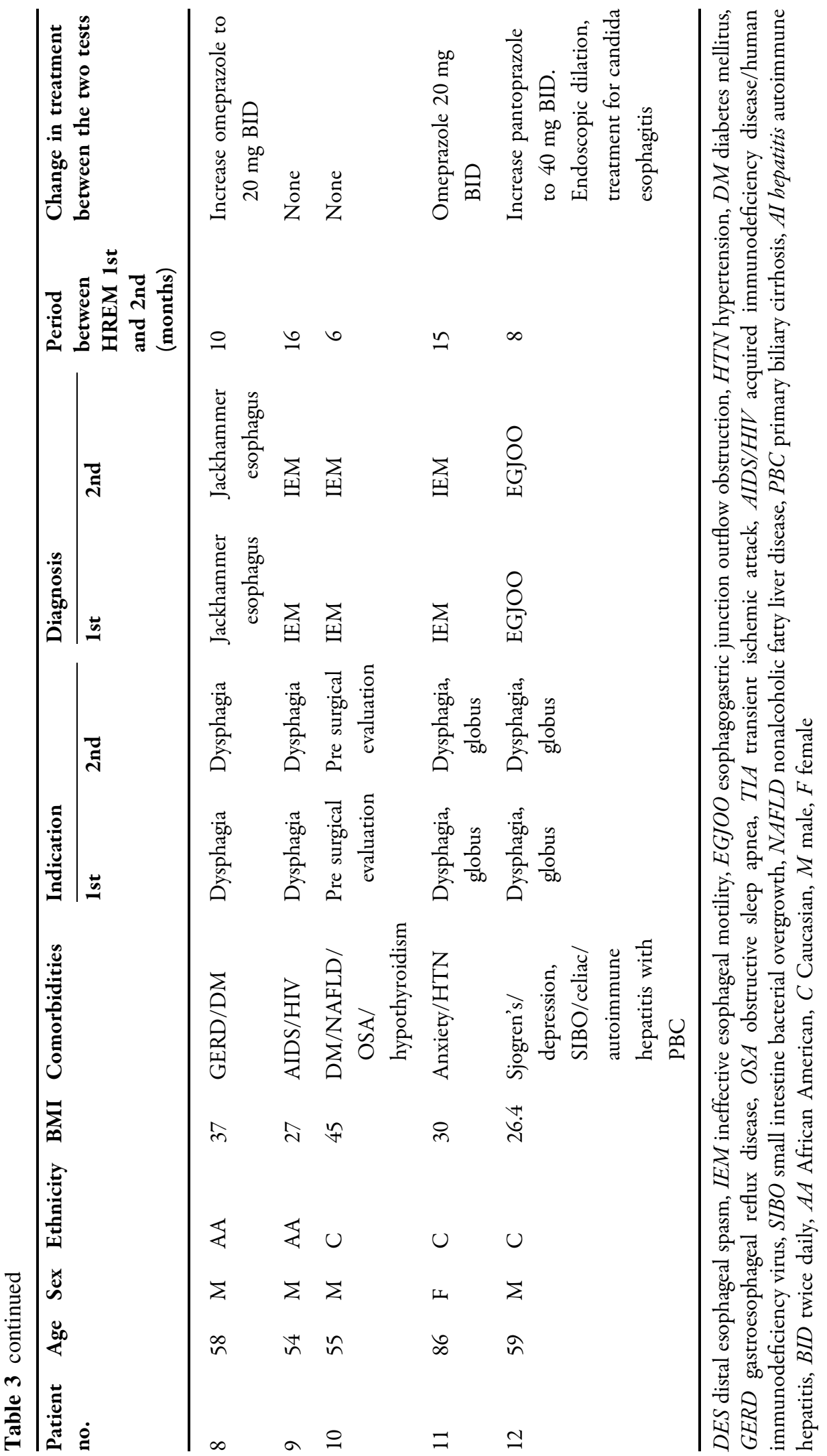


In the five patients who had worsening diagnoses on the second HREM study, three had their PPI increased to twice daily and one patient was started on twice-daily PPI therapy.

In the initial HREM of those with unchanged esophageal motility, half of the patients were on double-dose PPI therapy. Some of the interventions that were associated with improvement in HREM diagnoses were also done in these patients, but no change in HREM was noted. These included: esophageal dilation and lifestyle modifications. Two patients whose diagnosis of esophagogastric junction outlet obstruction and ineffective esophageal motility (IEM) did not change were on narcotics, which might explain the lack of improvement despite other interventions.

The period of time between the two HREM tests was similar. The median period of time between the two tests was 10 months (q1:8; q3:15) in all patients, 11 months for those with changed diagnosis (q1:9; q3:17) and 10 months for those without a change in diagnosis (q1:8; q3:12.7).

\section{DISCUSSION}

In this case series, we demonstrated that, for some patients, HREM diagnosis was transient and could change in both positive and negative directions. In the future, studies with large cohorts may be able to use HREM data to determine the durability and natural course of various esophageal motility disorders.

Of the 25 patients who were reviewed, 13 $(52 \%)$ had a different diagnosis at the time of the second HREM. Eight patients (62\%) had an improvement in diagnosis whereas 5 (38\%) had worsening diagnosis. Twelve patients $(48 \%)$ had no change in diagnosis between the two HREM studies.

Similar interventions were employed in the cases that showed improvement and worsening and those that remained unchanged. The most common therapeutic intervention was the addition of or increase in proton pump inhibitor dose. Initially, upon review, it was noted that in eight of the patients with improved diagnosis, seven had an increase in the PPI dose.
However, of the five patients who had a worsening diagnosis, all were also on increased PPI dose. In the cases in which patients had no change in follow-up HREM, two were also on increased PPI dose and four were receiving a PPI, albeit not in a maximal dose. In addition, there is limited evidence in the literature that treatment with any anti-reflux medication can alter esophageal function especially in patients with esophageal hypomotility, even after healing of erosive esophagitis. A study conducted by $\mathrm{Xu}$ et al. evaluated the relationship between esophageal motor disorders and PPI therapy. The study involved 12 healthy subjects and 100 patients with gastroesophageal reflux disease. All patients underwent HREM to assess for esophageal motility disorder. The study used a twopronged approach and assessed the esophageal motility of healthy subjects and then of those with non-erosive reflux disease, mild and severe erosive esophagitis. Patients in all groups were placed on $30 \mathrm{mg}$ lansoprazole daily. Findings showed that although esophageal dysmotility was noted in patients with both non-erosive reflux disease and erosive esophagitis, the healing of severe erosive esophagitis may not necessarily improve esophageal motility [10]. This supports our finding that the use of PPI may not alter esophageal motility.

The most common diagnosis that was encountered in our case series during both the first and second HREM was IEM. Overall, $32 \%$ of the patients had IEM as the initial diagnosis and $32 \%$ had IEM as the second diagnosis. The etiology of IEM is poorly understood, and unless these patients also have GERD then they are rather difficult to treat. One study evaluated the treatment of 46 patients with IEM. Patients underwent $\mathrm{pH}$ testing, and $58.7 \%$ were found to have abnormal esophageal acid exposure. Interestingly, PPI was more effective in treating symptoms of patients with IEM and abnormal esophageal acid exposure. Patients with IEM and normal esophageal acid exposure demonstrated no relief of symptoms with PPI therapy. The study concluded that if gastroesophageal reflux disease is not identified, then IEM is unlikely to respond to anti-reflux intervention [11]. It would have been helpful to have all patients with IEM in this case series undergo $\mathrm{pH}$ 
testing prior HREM and while on anti-reflux treatment in order to correlate between symptom improvement and normalization of esophageal acid exposure.

Other interventions were done between the two HREM studies that did not demonstrate a significant correlation with the diagnosis (improvement or worsening) on the second HREM. These interventions were not performed consistently, and they included lifestyle modifications, tricyclic antidepressants and use of prokinetic agents (metoclopramide/erythromycin). Given the lack of consistency in implementation, it is difficult to draw any conclusion regarding their effect on patients' esophageal motility.

The main limitation of the study is the small number of patients and lack of standardization in management and time to repeat HREM.

In summary, more than half of the patients undergoing repeat HREM after a period of 6-36 months demonstrated a different diagnosis, suggesting that diagnosed esophageal motor disorders may not necessarily be durable. No specific therapeutic intervention was associated with improvement or worsening of the initial HREM diagnosis. Our case series suggests that, in a subset of patients with non-achalasic esophageal motor disorders, repeat HREM at least 6 months later can be considered to assess for durability of the initially diagnosed motility abnormality. However, larger randomized prospective controlled trials are needed for a more definitive answer about the value of repeating HREM.

\section{ACKNOWLEDGEMENTS}

Funding. No funding or sponsorship was received for this study or publication of this article.

Authorship. All named authors meet the International Committee of Medical Journal Editors (ICMJE) criteria for authorship for this article, take responsibility for the integrity of the work as a whole and have given their approval for this version to be published.
Disclosures. The authors Annumeet Sandhum Mohamed Eisa, Takahisa Yamasaki and Fahmi Shibli have nothing to disclose. Ronnie Fass is an Editorial Board member of Advances in Therapy but has no other relevant disclosures.

Compliance with Ethics Guidelines. This study was approved by the institutional review board of MetroHealth Medical Center.

Data Availability. All data generated or analyzed during this study are included in this published article.

Open Access. This article is licensed under a Creative Commons Attribution-NonCommercial 4.0 International License, which permits any non-commercial use, sharing, adaptation, distribution and reproduction in any medium or format, as long as you give appropriate credit to the original author(s) and the source, provide a link to the Creative Commons licence, and indicate if changes were made. The images or other third party material in this article are included in the article's Creative Commons licence, unless indicated otherwise in a credit line to the material. If material is not included in the article's Creative Commons licence and your intended use is not permitted by statutory regulation or exceeds the permitted use, you will need to obtain permission directly from the copyright holder. To view a copy of this licence, visit http://creativecommons.org/licenses/by$\mathrm{nc} / 4.0 /$.

\section{REFERENCES}

1. Rohof WOA, Bredenoord AJ. Chicago classification of esophageal motility disorders: lessons learned. Curr Gastroenterol Rep. 2017;19(8):37.

2. Kahrilas PJ, Bredenoord AJ, Fox M, et al. The Chicago Classification of esophageal motility disorders, v3.0. Neurogastroenterol Motil. 2015;27(2):160-74.

3. Herregods TV, Roman S, Kahrilas PJ, Smout AJ, Bredenoord AJ. Normative values in esophageal high-resolution manometry. Neurogastroenterol Motil. 2015;27(2):175-87. 
4. Wang YT, Yazaki E, Sifrim D. High-resolution manometry: esophageal disorders not addressed by the "Chicago Classification". J Neurogastroenterol Motil. 2012;18(4):365-72.

5. Dalton CB, Castell DO, Richter JE. The changing faces of the nutcracker esophagus. Am J Gastroenterol. 1988;83(6):623-8.

6. Anggiansah A, Bright NF, McCullagh M, Owen WJ. Transition from nutcracker esophagus to achalasia. Dig Dis Sci. 1990;35(9):1162-6.

7. Paterson WG, Beck IT, Da Costa LR. Transition from nutcracker esophagus to achalasia. A case report. J Clin Gastroenterol. 1991;13(5):554-8.

8. Narducci F, Bassotti G, Gaburri M, Morelli A. Transition from nutcracker esophagus to diffuse esophageal spasm. Am J Gastroenterol. 1985;80(4): 242-4.

9. Abdallah J, Fass R. Progression of jackhammer esophagus to type II achalasia. J Neurogastroenterol Motil. 2016;22(1):153-6.

10. Xu JY, Xie XP, Song GQ, Hou XH. Healing of severe reflux esophagitis with PPI does not improve esophageal dysmotility. Dis Esophagus. 2007;20(4): 346-52.

11. Shetler KP, Bikhtii S, Triadafilopoulos G. Ineffective esophageal motility: clinical, manometric, and outcome characteristics in patients with and without abnormal esophageal acid exposure. Dis Esophagus. 2017;30(6):1-8. 